\title{
Molecular Recognition Force Spectroscopy for Probing Cell Targeted Nanoparticles In Vitro
}

\section{Gomes CP1,2,3,4, Oliveira H,6, Ebner A7, Hinterdorfer P7, Pêgo AP8,9,10,11}

1 Instituto de Engenharia Biomédica (INEB), Universidade do Porto, Porto, Portugal.

2 Instituto de Investigação e Inovação em Saúde (i3S), Universidade do Porto, Porto, Portugal.

3 Faculdade de Engenharia, Universidade do Porto, Porto, Portugal.

4 Faculdade de Medicina, Instituto de Medicina Molecular, Universidade de Lisboa, Lisboa, Portugal.

5 Tissue Bioengineering, University of Bordeaux, U1026, Bordeaux, France.

6 Tissue Bioengineering, Inserm, U1026, Bordeaux, France.

7 Institute of Biophysics, Johannes Kepler University Linz, Linz, Austria.

8 Instituto de Engenharia Biomédica (INEB), Universidade do Porto, Porto, Portugal. apego@ineb.up.pt.

9 Instituto de Investigação e Inovação em Saúde (i3S), Universidade do Porto, Porto, Portugal. apego@ineb.up.pt.

10 Faculdade de Engenharia, Universidade do Porto, Porto, Portugal. apego@ineb.up.pt. 11 Instituto de Ciências Biomédicas Abel Salazar (ICBAS), Universidade do Porto, Porto, Portugal. apego@ineb.up.pt.

Originally published in Methods Mol Biol. 2019;1886:327-341. doi: 10.1007/978-1-4939-8894-5_19

\begin{abstract}
In the development and design of cell targeted nanoparticle-based systems the density of targeting moieties plays a fundamental role in allowing maximal cell-specific interaction. Here, we describe the use of molecular recognition force spectroscopy as a valuable tool for the characterization and optimization of targeted nanoparticles toward attaining cell-specific interaction. By tailoring the density of targeting moieties at the nanoparticle surface, one can correlate the unbinding event probability between nanoparticles tethered to an atomic force microscopy tip and cells to the nanoparticle vectoring capacity. This novel approach allows for a rapid and cost-effective design of targeted nanomedicines reducing the need for long and tedious in vitro tests.
\end{abstract}

Key words Single molecule force spectroscopy, Tip functionalization, Targeted nanoparticles, Drug delivery, Tailored nanomedicine 


\section{INTRODUCTION}

Tailored drug-delivery systems have become increasingly important in the development of novel medical therapies and pharmaceutical products [1]. The use of targeted nanoparticles, which have the capability of encapsulating different therapeutic agents and preferentially delivering them to specific tissues and cells, hold the promise of revolutionizing the treatment of many diseases including cancer, cardiovascular, neurological and immunological disorders [2]. In this context, the optimal ligand density of targeting moieties in a nanoparticle-based system, allowing maximal cellspecific interaction, plays a fundamental role in the development and design of efficient targeted systems. However, the optimization of the density of targeting moieties implies tedious and timeconsuming in vitro studies.

In recent years, atomic force microscopy (AFM) has emerged as a powerful characterization platform in the field of biosciences, providing valuable insight into many biological processes that may have major implications for drug design and development [1]. Because of its piconewton force sensitivity and nanometer positional accuracy, the AFM enables the exploration of the forces and dynamics of the interaction between individual ligands and receptors, either on isolated molecules or on cellular surfaces $[3,4]$

Our group has previously proposed molecular recognition force spectroscopy (MRFS) as a valuable tool for the characterization and optimization of poly(ethylene imine) based nanoparticles complexed with plasmid DNA toward improving receptor-specific binding of the nanoparticle-based gene-delivery system to the ND7/23 neuronal cell line [5]. In more detail, the $50 \mathrm{kDa}$ nontoxic carboxylic fragment of the tetanus toxin ( $\mathrm{HC}$ fragment), known to specifically bind to the trisialoganglioside $\mathrm{GT}_{1} \mathrm{~b}$ receptor in the membrane of neuronal cells, was used as the targeting moiety for the development of ternary nanoparticles [6]. Both the HC fragment alone and the ternary nanoparticles were tethered to an AFM tip via hetero-bifunctional PEG-linkers as previously described [7-9], and probed against neuronal (sample) and fibroblasts (control) cells. Specific interactions with the ND7/23 cells had a similar binding probability of around $16 \%$ for both the $\mathrm{HC}$ fragment and the ternary nanoparticles, with a dramatic drop after blocking cell receptors with soluble $\mathrm{HC}$ fragment.

More recently, we took advantage of MRFS to evaluate the specificity of neuron-targeted trimethyl chitosan nanoparticles toward neuronal cell populations in biological models of higher complexity, such as primary mixed cultures as well as specific subcellular regions in histological tissue sections [10].

In conclusion, the use of MRFS allowed us to determine the optimal targeted nanoparticle formulation regarding neuronal cell internalization and transfection, as well as to obtain new insights into the ligand-receptor mechanism. The obtained results illustrate the potential of this novel approach for the rapid and cost-effective design of targeted nanoparticle systems, as MRFS has proved to be a reliable method that allows reproducible and comparable results independently of the biological model being tested (isolated cell lines, heterogeneous cultures, or tissue samples).

Although MRFS experiments are relatively straightforward to set up, there are critical steps such as sample preparation, AFM tip functionalization, and data evaluation that are of paramount importance to obtain suitable data. Taking this into consideration, in this chapter we present the 
protocol established by us for the evaluation of nanoparticles targeting potential toward isolated cell lines, as well as valuable tips for the experimental design and data interpretation.

\section{Materials}

Prepare all solutions using ultrapure water (prepared by purifying deionized water, to attain a resistivity of $18.18 \mathrm{M} \Omega . \mathrm{cm}$ at $25^{\circ} \mathrm{C}$ ) and analytical grade reagents. Prepare and store all reagents at room temperature (RT), unless indicated otherwise. Diligently follow all waste disposal regulations when disposing waste materials.

\subsection{Cell Culture}

1. $0.1 \%(w / v)$ poly(D-lysine) (PDL).

2. ND7/23 cells (mouse neuroblastoma ( $\left.\mathrm{N}_{18} \mathrm{tg} 2\right) \times$ rat dorsal root ganglion neuron hybrid cell line) (this neural cell line was selected as these cells express $\mathrm{HC}$ receptors) (see ref. 6).

3. NIH ${ }_{3} \mathrm{~T}_{3}$ cells (mouse embryonic fibroblasts) (control cell line; these cells do not express $\mathrm{HC}$ receptors-see ref. 6).

4. Dulbecco's Modified Eagle's Medium (DMEM).

5. Fetal bovine serum (FBS) (heat inactivated at $57^{\circ} \mathrm{C}$ for $30 \mathrm{~min}$ ).

6. Antibiotic solution (P/S: 10,000 U. $\mathrm{mL}^{-1}$ penicillin and 10,000 $\mu \mathrm{g} \cdot \mathrm{mL}^{-1}$ streptomycin).

7. Tissue culture polystyrene flasks.

8. Polystyrene Petri dishes $(35 \times 10 \mathrm{~mm})$.

9. $4 \%(\mathrm{w} / \mathrm{v})$ paraformaldehyde.

10. Phosphate-buffered saline (PBS) solution.

11. Glass coverslips (diameter $22 \mathrm{~mm}$ )

12. Tweezers.

13. Sterilization filters ( $0.22 \mu \mathrm{m}$ pore) and syringes.

\subsection{Nanoparticle Preparation}

1. Thiolated poly(ethylene imine)_PEISH (for further details on the synthesis of the modified polymer see ref. 6). 
2. Plasmid DNA (in this report we considered a $7.4 \mathrm{~kb}$ plasmid encoding for the green fluorescent protein (GFP) under a CMV promoter).

3. $5 \%(\mathrm{w} / \mathrm{v})$ glucose solution $(\mathrm{pH} 7.4)$.

4. HC fragment (see Note 1).

5. Phosphate buffer ( $\mathrm{pH} 8)$.

6. Hetero-bifunctional 5 kDa PEG bearing an N-hydroxysuccinimide (NHS) and a maleimide end group (Maleimide-PEG10o- NHS).

\subsection{Tip Functionalization}

1. Aminopropyltriethoxysilane (APTES).

2. Chloroform.

3. Triethylamine (TEA).

4. Sodium cyanoborohydride, $\mathrm{NaCNBH}_{3}$.

5. Ethanolamine.

6. $1 \%(v / v)$ citric acid prepared in ultrapure water.

7. Sodium hydroxide, $\mathrm{NaOH}$.

8. EDTA disodium salt (EDTA-Na2 $\left.\cdot \mathrm{H}_{2} \mathrm{O}\right)$.

9. 4-(2-hydroxyethyl)-1-piperazineethanesulfonic acid, HEPES.

10. Tris(carboxyethyl)phosphine hydrochloride (TCEP) hydrochloride.

11. PBS.

12. HC fragment (see Note 1).

13. Hetero-bifunctional PEG (80o kDa) bearing an NHS and an acetal end group (Acetal-PEG18-NHS).

14. Hetero-bifunctional PEG (80o kDa) bearing an NHS and a maleimide end group (MaleimidePEG18-NHS).

15. Polystyrene Petri dishes.

16. Parafilm "M"®. 
17. Silicon nitride AFM cantilevers with nominal spring constants ranging from 0.01 to $0.05 \mathrm{~N} \mathrm{~m}^{-1}$ (MSCT, Bruker).

\subsection{Others}

1. Gold-coated mica surface (Agilent Technologies or commercially available gold-coated mica).

2. Nitrogen gas source (purity 99.9992\%).

3. Argon gas source (purity 99.9997\%).

4. Tweezers.

5. Glass pipettes.

6. Micropipettes and pipette tips.

7. Glass desiccator (5 L).

\subsection{Equipment}

1. PicoPlus 5500 AFM setup and fluid cell equipped with flow cell (Agilent Technologies).

2. CCD camera.

3. Laminar flow hood (Type II).

4. Cell incubator.

\section{Methods}

\subsection{Cell Sample Preparation}

Cell handling and media preparation should be performed in a laminar flow hood under aseptic conditions.

1. $\mathrm{ND}_{7} / 23$ and $\mathrm{NIH} 3_{3} \mathrm{~T}_{3}$ cells should be grown in complete DMEM medium (with $10 \%(\mathrm{v} / \mathrm{v})$ heatinactivated $\mathrm{FBS}$ and $1 \%(\mathrm{v} / \mathrm{v}) \mathrm{P} / \mathrm{S}$ ) under $5 \% \mathrm{CO}_{2}$ at $37^{\circ} \mathrm{C}$. Renew culture medium

every other day and subculture cells at $80 \%$ confluence.

2. Seed cells on PDL-coated glass coverslips placed inside a Petri dish (see Note 2 ) in order to achieve a confluence state of around $50 \%$.

3. One or two days after cell seeding remove media, wash cells with warm PBS $\left(37^{\circ} \mathrm{C}\right)$, and fix cells with $4 \%(w / v)$ paraformaldehyde for $20 \mathrm{~min}$ at RT (see Note 3 ).

INSTITUTO DE INVESTİGAÇÃO EINOVAÇAO

EM SAUDE

UNIVERSIDADE

DO PORTO 
4. Wash cells twice with PBS, close the Petri dish with Parafilm " $\mathrm{M}^{\prime \prime}{ }^{\circledR}$, and store them at $4^{\circ} \mathrm{C}$ until further use (when no sodium azide is used cells can be stored up to 2 weeks).

\subsection{Nanoparticle Preparation}

1. After production and purification of the $H C$ fragment (see Note 1), incubate the protein solution with the heterobifunctional Maleimide-PEG100-NHS, at a 2.5 $\mathrm{PEG} / \mathrm{HC}$ protein molar ratio (for further details see ref. 6).

2. Prepare the nanoparticle core by mixing, while vortexing, equal volumes of plasmid DNA and

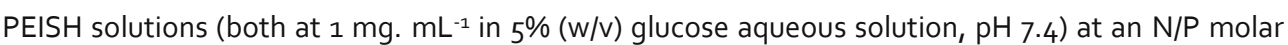
ratio of 3 (see Note 4 ).

3. Incubate the complex mixture for $15 \mathrm{~min}$ at RT to allow for

nanoparticle formation and stabilization.

4. Subsequently, add the HC previously coupled with PEG at a final concentration ranging from 1.25 to $7.5 \mu \mathrm{g}$ per $2 \mu \mathrm{g}$ of plasmid DNA to the complex mixture and immediately use for AFM tip functionalization with the maleimide linkers (see Subheading 3.5).

\subsection{AFM Tip Amino-Functionalization with APTES}

Perform the whole procedure in a well-ventilated hood (see Note 5).

1. Wash the AFM cantilevers in chloroform for $3 \times 5$ min. Every washing step should be performed using a clean beaker with fresh chloroform. Finally, dry the AFM cantilevers in a stream of nitrogen gas.

2. Flush desiccator chamber with argon gas.

3. Place one tray with $30 \mu \mathrm{L}$ APTES and another tray with $10 \mu \mathrm{L}$ TEA in the desiccator (see Note 6).

4. Place the cantilevers in the desiccator close to the two trays,

close the desiccator lid, and incubate for $2 \mathrm{~h}$.

5. Remove the trays containing APTES and TEA and flush the desiccator with argon. Subsequently place the tips under argon atmosphere for at least 2 days ("curing").

6. Store the tips under argon in a dust-free box for up to 3 weeks.

\subsection{AFM Tip Functionalization with Acetal Linkers}

Perform the whole procedure in a well-ventilated hood. 
1. Dissolve $1 \mathrm{mg}$ of the acetal-PEG18-NHS linker in $0.5 \mathrm{~mL}$ chloroform, transfer the solution into a small container (the tips must fit and be fully covered with the liquid), add TEA ( $30 \mu \mathrm{L}$ ), and mix (see Note 7).

2. Immediately place the APTES functionalized cantilever(s) in the same container, cover with lid to prevent chloroform evaporation, and incubate for $2 \mathrm{~h}$.

3. Wash with chloroform ( $3 \times 10 \mathrm{~min})$ and dry with nitrogen gas.

4. Store cantilever(s) for up to several weeks under argon or continue with next step.

5. Immerse cantilever(s) for $10 \mathrm{~min}$ in $1 \%(\mathrm{v} / \mathrm{v})$ citric acid.

6. Wash cantilever(s) in ultrapure water $(3 \times 5 \mathrm{~min})$, dry with nitrogen gas, and immediately continue to the next step.

7. Place the cantilever(s) on a piece of Parafilm " $\mathrm{M}$ " $\odot$ in a polystyrene Petri dish: to do so, a piece of Parafilm " $\mathrm{M}$ " ${ }^{\circledR}$ is pressed onto the inner surface of a polystyrene Petri dish and several cantilevers are placed onto the Parafilm " $\mathrm{M}$ " ${ }^{\circledR}$ in a radial arrangement, with the tips in the center and facing upward. The tipped ends should be so close together so that one droplet of the protein solution covers all tips at the same time.

8. Pipette $100 \mu \mathrm{L}$ protein solution ( $1 \mu \mathrm{M})$ onto the cantilever(s).

9. Add $2 \mu \mathrm{L}$ of a freshly prepared $1 \mathrm{M}$ of sodium cyanoborohydride solution (with $20 \mathrm{mM} \mathrm{NaOH}$ ), mix carefully into the protein solution droplet with the pipette, cover with lid, and incubate for $1 \mathrm{~h}$ (see Note 8).

10. Add $5 \mu \mathrm{L}$ of ethanolamine ( $1 \mathrm{M}, \mathrm{pH}$ 8.0) to the drop on the cantilever(s), mix cautiously, cover with lid, and incubate for another $10 \mathrm{~min}$.

11. Wash in PBS ( $3 \times 5$ min).

12. Mount cantilever in AFM setup (or store immersed in PBS containing $0.02 \%(v / v)$ sodium azide at $4^{\circ} \mathrm{C}$, up to $1-2$ weeks) (see Fig. 1a).

\subsection{AFM Tip Functionalization with Maleimide Linkers}

Perform the whole procedure in a well-ventilated hood.

1. Dissolve $1 \mathrm{mg}$ of the maleimide-PEG18-NHS in $0.5 \mathrm{~mL}$ chloroform, transfer the solution into a small container, add TEA $(30 \mu \mathrm{L})$, and mix.

2. Immediately place cantilever(s) into the container, cover with lid, and incubate for $2 \mathrm{~h}$.

3. Wash with chloroform ( $3 \times 10 \mathrm{~min})$ and dry with nitrogen gas. Continue with next step. 

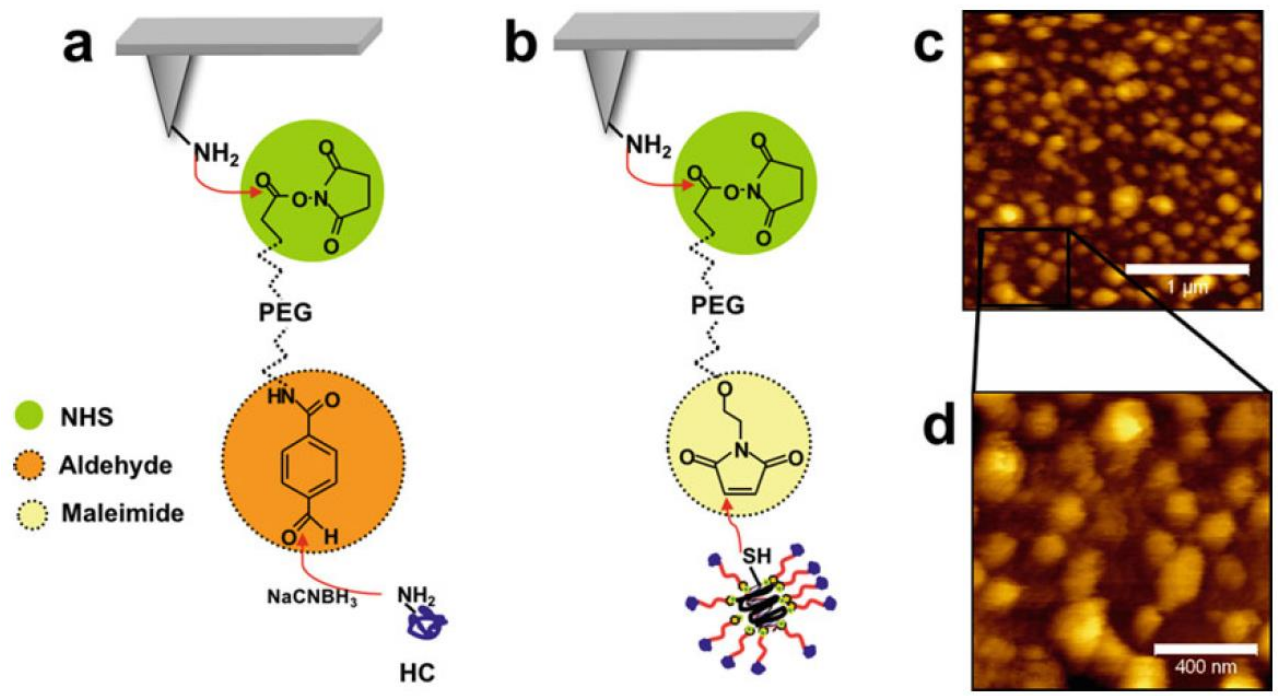

Fig. 1 Schematic representation of the chemical tethering strategies used to bind the nontoxic carboxylic fragment from the tetanus toxin ( $\mathrm{HC}$ fragment) (a) and the functionalized nanoparticles (b) to the AFM tip via a hetero-bifunctional PEG18. Both tips were amino-functionalized using 3aminopropyltriethoxysilane (APTES). The tethering of the nanoparticles was confirmed by imaging the surface of the cantilever using magnetic AC mode (c) and therefore single nanoparticles could be resolved by AFM imaging (d) (adapted from ref. 5 with permission from John Wiley and Sons)

4. Place cantilever(s) on a piece of Parafilm " $\mathrm{M}$ " $\circledast$ in a polystyrene Petri dish. 5. Pre-mix the following components (see Note 9):

(a) $100 \mu \mathrm{L}$ nanoparticle dispersion in $5 \%(\mathrm{w} / \mathrm{v})$ glucose

$\left(\mathrm{pH}_{7.4)}\right.$ (see Note 10).

(b) $2 \mu \mathrm{L}$ EDTA (100 mM, pH 7.5).

(c) $5 \mu \mathrm{L}$ HEPES (1 M, pH 7.5).

Version: Postprint (identical content as published paper) This is a self-archived document from i3S - Instituto de Investigação e Inovação em Saúde in the University of Porto Open Repository For Open Access to more of our publications, please visit http://repositorio-aberto.up.pt/ 
(d) $2 \mu \mathrm{L}$ TCEP hydrochloride (100 mM).

(e) $2 \mu \mathrm{L} \operatorname{HEPES}(1 \mathrm{M}, \mathrm{pH}$ 9.6) - or more if the thiol component is in a strongly acidic solution.

6. Pipet the mixture onto the cantilever(s), cover with lid, and incubate for $2-4 \mathrm{~h}$.

7. Wash in PBS or any other buffer of choice (3- $5 \mathrm{~min})$.

8. Mount cantilever in AFM setup (or store immersed in PBS at $4^{\circ} \mathrm{C}$ for $1-2$ weeks) (see Fig. 1b).

\subsection{Force Measurements}

1. Clean tweezers and the AFM fluid cell with a mild detergent solution ( $1 \%(w / v)$ SDS in water), rinse extensively with ultrapure water and, finally, with ethanol. Air-dry.

a

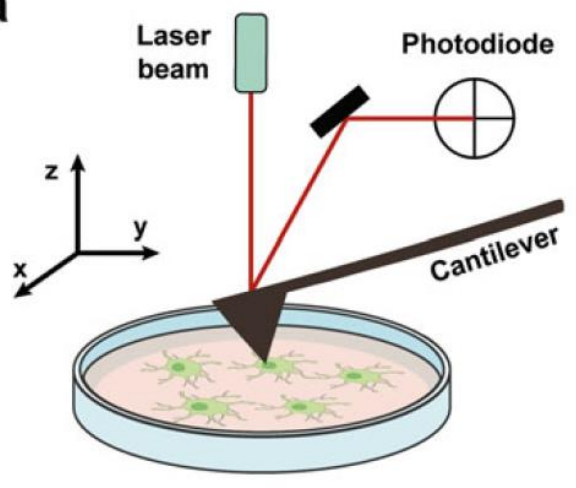

b

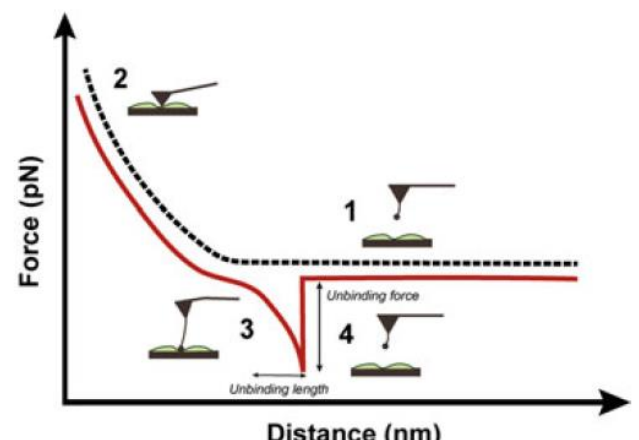

Fig. 2 Typical setup of an AFM instrument (a). The tip-sample interactions can arise from a variety of forces (electrostatic, van der Waals, capillary, chemical, etc.) and yields the cantilever deflection, which is detected by using a laser beam reflecting off the back of the cantilever onto a positionsensitive photodiode. Schematic representation of a force-distance cycle representative of a specific unbinding event for a single biomolecular complex (b). The force is plotted against the piezo traveling distance. As the functionalized AFM tip approaches the cell sample surface (black dotted line, 1), the ligand encounters its paired receptor, resulting in the cantilever deflection (2). Subsequently, the tip is pulled away from the surface (red solid line), which leads to the linker stretching and causes nonlinearity in the curve (3) and the force continues to increase until the rupture of the ligandreceptor bond (4)

2. Place the glass coverslip containing cell samples onto the goldcoated mica (see Note 11) and place them on the AFM sample plate (see Note 12). 
3. Gently wash the cell sample with PBS at RT three to five times to remove any loose cells. Fill the fluid cell with PBS until it is fully covered. Ensure that the liquid is not leaking (see Note 13).

4. Allow the AFM setup to thermo-stabilize for about $30 \mathrm{~min}$ before use. Meanwhile, set the program to conventional contact mode. Place the AFM scanner into the AFM station and adjust the position with the sample stage to allow enough space between them (see Note 14).

5. Insert the functionalized cantilever into the AFM scanner. Assemble the AFM fluid cell with care and let the system to equilibrate for $10 \mathrm{~min}$ to minimize thermal drift. During this time, adjust the CCD camera to clearly see the cells underneath the AFM tip. Localize the tip above an isolated cell. Thereafter, align and focus the laser beam onto the cantilever end and adjust the photodiode signal to zero (see Note 15 and Fig. 2a).

6. Approach the functionalized AFM tip toward cells using the contact mode. Select cells that are firmly attached and have a flat-shaped morphology. Avoid round-shaped cells that are loosely attached to the surface as this may indicate that at the time of fixation they were detaching, undergoing apoptosis or already dead. These cells can adsorb to the AFM tip and damage it.

7. Open the conventional contact force calibration plot mode. Set the sweep amplitude of the forcedistance cycle to $1 \mathrm{~Hz}$ vertical sweeping frequency and $500 \mathrm{~nm}$ z-range (see Note 16 ).

8. Start the force-distance cycle acquisition (see Fig. 2b) and slightly lower the cantilever closer to the cell surface until you achieve optimal contact (see Note 17).

9. Observe the unbinding events in the force-distance curves. For each cell, record at least 1000 forcedistance curves, changing the tip position (to an area nearby within the same cell, without withdrawing) every 200 curves to ensure statistical significance.

10. Withdraw the tip and reapproach again on a different cell. Ensure that the laser spot has not moved (see Note 18). Repeat the recording of force-distance curves on at least five different cells (see Note 19).

\subsection{Proof of Specificity}

1. Withdraw the tip from the sample by $200 \mu \mathrm{m}$ (see Note 20).

2. Remove the sample and add soluble protein solution (HC protein) to the cell medium in order to achieve a final concentration of $1 \mathrm{mg} \cdot \mathrm{mL}-1$ (see Note 21 ).

3. Mount the liquid cell on the AFM setup and incubate the system for $1 \mathrm{~h}$ to allow the blocking molecules to distribute homogenously in the system.

4. Reapproach the tip toward the sample and record force-distance curves as previously mentioned (see Notes 22 and 23).

5. Withdraw the tip by $200 \mu \mathrm{m}$ from the surface, remove the liquid cell from the AFM setup, and gently wash the surface several times with PBS.

INSTITUTO DE INVESTİGAÇÃO E INOVAÇÃO EM SAÚDE UNIVERSIDADE DO PORTO 
6. Mount the liquid cell into the system, approach the tip as previously mentioned, and repeat the force-distance curves as described. If the blocking ligands are completely removed, unbinding events similar to the initial conditions should be observed (see Note 23 and Fig. 3). If this is the case, the block-washout experiment is now completed and will confirm the specificity of the functionalized AFM tip (see Note 18).

\subsection{Data Analysis}

All numerical calculations were performed using the matrixoriented computer environment MatLab ${ }^{\text {TM }}$ Version R2oogb (MATH WORKS Inc.) and the previous described algorithms were used to find the position of unbinding events and calculate the respective unbinding forces (see ref. 11).

1. For each data set with a given tip, determine the cantilever deflection sensitivity. This value depends on the type of the cantilever, but also on the optical path of the AFM detection laser and will be slightly different each time the cantilever is mounted in the instrument. To do so, record a few forcedistance curves on a cell-free zone of the glass coverslip (bare hard substrate) (see Note 24).
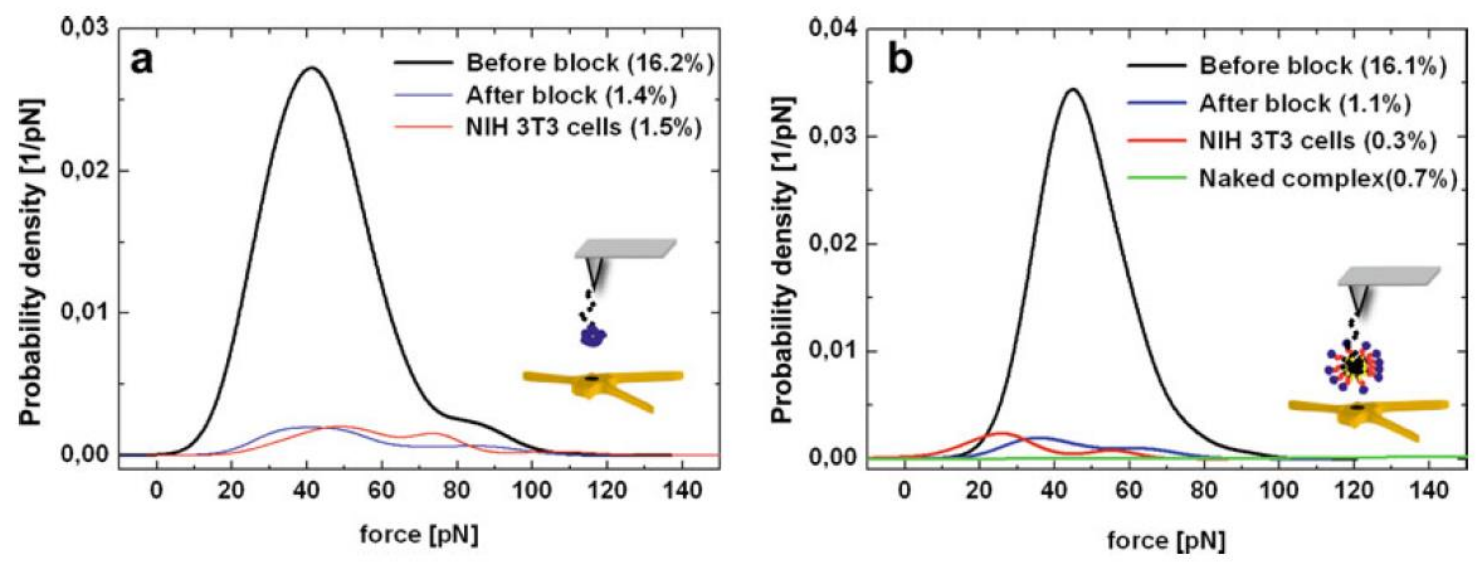

Fig. 3 Probability density function of rupture forces considering the interaction between the isolated $\mathrm{HC}$ fragment (a) or the ternary nanoparticles (b) and neuronal cells. To determine the specificity of each functionalized tip, controls were performed by surface blocking with free $\mathrm{HC}$ fragment (0.1 $\mathrm{mg} \cdot \mathrm{mL}-1$ for $1 \mathrm{~h}$; after block), in the control cell line ( $\mathrm{NIH}_{3} \mathrm{~T}_{3}$ cells) or using nanoparticles lacking the HC moieties (naked complex). The unbinding probability of each condition is presented inside parentheses (adapted from ref. 5 with permission from John Wiley and Sons)

2. Separately analyze the results acquired for each condition, i.e., initial condition, block experiment, and washout for each cantilever used. Detect the unbinding events that present the unique characteristic shape of specific interaction between ligand-receptor in the retrace curves (see Note 25).

3. For quantitative analysis of the unbinding forces determine the spring constants of the functionalized cantilevers, so that the deflection of the cantilever can be converted into actual force values (F), using the well-known Hooke's law: 


$$
\mathrm{F}=k x
$$

where $\mathrm{k}$ represents the cantilever spring constant and $\mathrm{x}$ the known distance of the cantilever deflection. For this calibration we used the thermal noise method $[12,13]$. This is the most widely and commonly accepted method for cantilever spring constant determination.

\section{Notes}

1. The HC fragment was produced recombinantly using the BL21 E. coli strain. The plasmid encoding for the $\mathrm{HC}$ fragment, together with a coding sequence for six histidines at the $\mathrm{N}$ terminal, was a kind offer from Prof. Neil Fairweather (King's College, UK). For further details on the protocol for HC production and purification refer to ref. 14 .

2. Immobilization of cells depends mainly on the cell type and on the substrate where the cells grow. Here cells are to be seeded on glass coverslips, so prior to cell seeding the glass slides have to be coated with an adhesive coating. Briefly, before cell seeding glass coverslips were cleaned with $70 \%$ $(\mathrm{v} / \mathrm{v})$ ethanol overnight. Afterward, they were rinsed in absolute ethanol and air-dried under sterile conditions. The coverslips were placed in small Petri dishes $(35 \times 10 \mathrm{~mm})$ and $2 \mathrm{~mL}$ of $0.1 \%(\mathrm{w} / \mathrm{v})$ of PDL (prepared in ultrapure water; after preparation, the solution was sterilized by passing through a $0.22 \mu \mathrm{m}$ filter, aliquoted, and stored at $-20^{\circ} \mathrm{C}$ for up to 1 year) was added onto the glass. After an incubation period of $1 \mathrm{~h}$ at $37^{\circ} \mathrm{C}$, the solution was removed and coverslips were washed twice with sterile ultrapure water and air-dried. After this procedure, the glass coverslips can be used directly or stored (seal the containers) in the refrigerator at $4^{\circ} \mathrm{C}$ for up to 1 day.

3. Depending on the cell growth rate, the time of cell culture required to achieve optimal cell density may vary. As soon as cells are adhered to the coverslips, they can be fixed. The duration and reagent used for fixation can vary depending on the cell type used and on the ligand-receptor pair. Ideally, cells should be used live if you have a setup that allows temperature and $\mathrm{CO}_{2}$ control. Otherwise, select fixation conditions that do not alter the ligand-receptor bond properties (e.g., an immunocytochemistry experiment could be performed using a labeled peptide/antibody to confirm the selective binding and interaction of the ligand-receptor pair under the chosen fixation conditions).

4. The N/P ratio stands for the ratio of free amino groups from the polymer $(\mathrm{N})$ and the phosphate groups from the plasmid DNA $(P)$.

5. Factors to be considered during tip functionalization include:

(a) The selection of a suitable AFM probe is critical, the key factors being sharpness of the tip and the cantilever's spring constant.

(b) The selection of tip functionalization chemistry - the ligand molecule must be connected to the tip so that the binding strength between the tip and the molecule is higher than the interaction between the molecule and the surface receptor.

INSTITUTO DE INVESTİGAÇÃO EINOVAÇÃO EM SAÚDE UNIVERSIDADE DO PORTO 
(c) The temperature, buffer composition, and $\mathrm{pH}$ must be carefully chosen during tip functionalization and force measurements, so the binding activity of the molecule is not altered.

(d) The correct orientation and function of the attached molecule are crucial for proper binding experiments.

6. The reagent APTES must not contain any aggregates; therefore, it must be used immediately after purchase. Any contact with humidity has to be avoided. Thus, it has to be transferred into the desiccator as fast as possible. Alternatively, it can be redistilled under vacuum. New (or redistilled) APTES can be kept "fresh" if small aliquots are sealed in crimp vials under argon gas and stored at $20^{\circ} \mathrm{C}$ for no longer than 12 months.

7. You can functionalize as many cantilevers as you can fit into the small container. We never functionalized less than five or more than ten. Do not move the container after putting the cantilevers inside, otherwise you can break the cantilevers tips. The acetal linking method is not applicable if the protein sample contains buffer components with primary amines, ammonium bicarbonate, or ammonium acetate. It also does not work for proteins stored in the presence of detergent. Pipetting of chloroform or TEA should be performed with glass pipettes and a pipette bulb (or with a graduated glass capillary in case of TEA) and not with the plastic tips of pipettes because the contact of the solvent with the plastic tips may lead to the presence of extractable compounds in the chloroform and/or TEA that in turn can interfere with the process. Similarly, you should pay attention to the material of the small container used for tips functionalization (do not use a plastic container).

8. Extreme caution is necessary when weighing the aliquots of $\mathrm{NaCNBH}_{3}$. Use a gas mask, a lab coat, and gloves for weighing. All material transfers must be performed in a wellventilated hood. For proper waste, dissolve three pellets of $\mathrm{NaOH}$ in $500 \mathrm{~mL}$ tap water, add the unused $\mathrm{NaCNBH}_{3}$ solution, mix, pour into the drain, and flush with tap water.

9. The order of the pipetting steps is critical and must not be changed. The sequence of pipetting steps has been optimized to minimize the adverse effect of air on TCEP and on the thiol component. The amount of EDTA is necessary (and sufficient) to prevent reoxidation during the coupling procedure on a time scale of few hours. For longer reaction times, it is advantageous to conduct the reaction under argon. Optimal $\mathrm{pH}$ conditions should be tested for different nanoparticle dispersion formulations.

10. The buffer of the thiol molecule to couple to the maleimide linker should not contain amino groups, 2-mercaptoethanol, dithiothreitol, dithioerythrol, or glutathione reagents.

11. The use of a gold-coated mica helps to achieve a better contrast on an image recorded with a CCD camera when observing cells and AFM tips.

12. When mounting the AFM fluid cell on the sample plate it is important to ensure that no air bubbles are trapped within the fluid cell assembly, as they will interfere with the AFM measurements.

13. The PBS solution should be filtered before its usage in the AFM fluid cell to avoid the presence of particles that could contaminate the sample. These can obstruct the cantilever and affect the purity of the sample. 
14. The space between the AFM scanner and the AFM sample stage should be adequate for the thickness of the sample, glass, and gold-coated mica to avoid damage to the coated tip.

15. It is important to maintain the functionalized tips permanently in liquid; otherwise the ligands may denature (this is particularly relevant for proteins or antibodies). This can be achieved by placing one drop of buffer on the tip of the AFM cantilever after mounting it on the AFM scanner.

16. You can reduce or increase the sweep amplitude and distance range depending on the cell type and the ligand-receptor pair. After you have found an appropriate sweep amplitude, keep the value constant throughout the experiment. Sweep amplitude or the speed of the retraction rate must be indicated in the results of the unbinding forces. Varying the speed of the tip movement can give further information about the ligandreceptor pair. The approach and retraction rates can be varied independently and waiting times can be added at the surface or at the retraction position. Moreover, as the rupture force distributions depend on the speed of the retraction rate (more precisely, the loading rate), varying the pulling rate can be useful for studying the dynamics of unbinding $[15,16]$.

17. When performing force spectroscopy in cells be careful not to use high forces in contact mode, as it can cause damage to the cells membrane. We recommend not using forces above $200 \mathrm{pN}$.

18. If, after trying all functionalized tips from the same batch of cantilevers, you could not observe any unbinding events, you should try one of the following procedures: (a) functionalize a new batch of cantilevers and perform longer incubation times at each step and (b) use a new batch of cells. If there is still no success, it is probably a result of a problem with the cell system (low density of receptors at the cell surface for the ligand being tested or inaccessibility of the binding site to the specific ligand), wrong buffer or $\mathrm{pH}$ composition (for instance, lack of specific ions required for binding).

19. The number of cells necessary to achieve good statistic strength will depend on the ligandreceptor pair and on the number of unbinding events in your sample versus your controls. The higher the number of cells tested, the higher the confidence level you can attain on your results.

20. You should continue with the same tip, in order to prove specificity for the unbinding events obtained in the force measurements.

21. Unequivocal demonstration of binding specificity through competitive binding, which eliminates measurable binding events using a soluble agonist, ion-dependent disruption of receptor binding or blocking/cleaving of the tip bound ligand is absolutely necessary.

22. Move the tip carefully when you change to a new location to avoid crashing the tip. The position of the cantilever in the scanner and the laser spot must not be moved; otherwise, both deflection sensitivity and spring constant need to be reassessed (see Subheading 3.8).

23. In block experiments, the unbinding events should be rare or disappear completely (or at least be statistically significantly lower). The incubation time also depends on each biological system. For some systems, buffer conditions can be changed to observe specificity of binding. 
24. This method will allow for the determination of the tip deflection in nanometers for a given movement of the detection laser on the photodetector. Since the hard repulsive interaction regime is used for the sensitivity measurement, it should be performed at the end of an experiment, to avoid damaging the tip.

25. To determine whether the unbinding events observed are specific for the proteins under investigation, compare cells that express the receptor with those that do not express it. For our experiments, we use a sensorial neuronal-like cell line that express receptors for the HC protein and a mouse fibroblasts cell line that do not express $\mathrm{HC}$ receptors as control (see ref. 6). If you observe the rare occurrence of multiple binding events and adhesion curves, exclude them from further analysis. The use of a flexible PEG cross-linker allows the distinction between specific binding and nonspecific adhesion by observing the polymer stretching in the retrace curve.

\section{Acknowledgements}

The authors would like to acknowledge the Bioimaging Platform (i3S-INEB) for the support with atomic force microscopy. This work was financed by projects NORTE-01-0145-FEDER-000008 and NORTE-01-0145-FEDER-000012, supported by Norte Portugal Regional Operational Programme (NORTE 2020), under the PORTUGAL 2020 Partnership Agreement, through the European Regional Development Fund (ERDF) and FEDER - Fundo Europeu de Desenvolvimento Regional funds through the COMPETE 2020 - Operacional Programme for Competitiveness and Internationalisation (POCI), Portugal 2020; and by Portuguese funds through FCT (Fundação para a Ciência e a Tecnologia) in the framework of the projects UID/BIM/04293/2013, PTDC/CTM-NAN/115124/2009, and PTDC/CTMNAN/3547/2014. C.P. Gomes acknowledge FCT for her PhD scholarship SFRH/BD/79930/2011.

\section{REFERENCES}

1 Lamprecht C, Hinterdorfer P, Ebner A (2014) Applications of biosensing atomic force microscopy in monitoring drug and nanoparticle delivery. Expert Opin Drug Deliv 11(8):1237-1253

2 Riehemann K, Schneider SW, Luger TA, Godin B, Ferrari M, Fuchs H (2009) Nanomedicine-challenge and perspectives. Angew Chem Int Ed Engl 48(5):872-897

3 Hinterdorfer P, Dufrêne YF (2006) Detection and localization of single molecular recognition events using atomic force microscopy. Nat Methods 3(5):347-355

4 Hinterdorfer P, Baumgartner W, Gruber HJ, Schilcher K, Schindler H (1996) Detection and localization of individual antibody-antigen recognition events by atomic force microscopy. Proc Natl Acad Sci 93(8):3477-3481

5 Oliveira H, Rangl M, Ebner A, Mayer B, Hinterdorfer P, Pêgo AP (2011) Molecular recognition force spectroscopy: a new tool to tailor targeted nanoparticles. Small 7(9):1236-1241

6 Oliveira H, Fernandez R, Pires LR, Martins MCL, Simões S, Barbosa MA, Pêgo AP (2010) Targeted gene delivery into peripheral sensorial neurons mediated by self-assembled vectors composed of poly(ethylene imine) and tetanus toxin fragment c. J Control Release 143(3):350-358

7 Ebner A, Hinterdorfer P, Gruber H (2007) Comparison of different aminofunctionalization strategies for attachment of single antibodies to AFM cantilevers. Ultramicroscopy 107(10-11):922-927 
8 Ebner A, Wildling L, Kamruzzahan A, Rankl C, Wruss J, Hahn C, Hölzl M, Zhu R, Kienberger F, Blaas D, Hinterdorfer $\mathrm{P}$, Gruber $\mathrm{H}$ (2007) A new, simple method for linking of antibodies to atomic force microscopy tips. Bioconjug Chem 18(4):1176-1184

9 Wildling L, Unterauer B, Zhu R, Rupprecht A, Haselgrubler T, RankI C, Ebner A, Vater D, Pollheimer P, Pohl EE, Hinterdorfer $P$, Gruber HJ (2011) Linking of sensor molecules with amino groups to amino-functionalized AFM tips. Bioconjug Chem 22(6):1239-1248

10 Gomes CP, Lopes CDF, Leitner M, Ebner A, Hinterdorfer P, Pêgo AP (2017) Atomic force microscopy as a tool to assess the specificity of targeted nanoparticles in biological models of high complexity. Adv Healthc Mater 6(21):1700597

11 Baumgartner W, Hinterdorfer $P$, Schindler H (2000) Data analysis of interaction forces measured with the atomic force microscope. Ultramicroscopy 82(1):85-95

12 Butt H-J, Jaschke M (1995) Calculation of thermal noise in atomic force microscopy. Nanotechnology 6(1):1

13 Hutter J, Bechhoefer J (1993) Calibration of atomic force microscopy cantilevers. Rev Sci Instrum 66:1868-1873

14 Sinha K, Box M, Lalli G, Schiavo G, Schneider H, Groves M, Siligardi G, Fairweather N (2000) Analysis of mutants of tetanus toxin $\mathrm{HC}$ fragment: ganglioside binding, cell binding and retrograde axonal transport properties. Mol Microbiol 37(5):1041-1051

15 Evans E, Ritchie K (1997) Dynamic strength of molecular adhesion bonds. Biophys J 72(4):1541-1555

16 Evans E, Ritchie K (1999) Strength of a weak bond connecting flexible polymer chains. Biophys J 76(5):24392447 